\title{
An application of data envelopment analysis on marble factories
}

Sinan Saraçli ${ }^{*}$, İbrahim Kiliç², Illkay Doğan² and Cengiz Gazeloğlu

"Correspondence:

ssaracli@aku.edu.tr

'Department of Statistics, Faculty of Art and Science, Afyon Kocatepe

University, Afyonkarahisar, TR-03200, Turkey

Full list of author information is available at the end of the article

\begin{abstract}
Purpose: The purpose of this study is to examine the efficiencies of marble factories in Afyonkarahisar city via data envelopment analysis (DEA), which is a mathematical programming-based analysis.

Methods: In this study, the efficiencies of 64 marble factories in Afyonkarahisar city, the most famous city in terms of marble production in Turkey, were examined. DEA was used to determine efficient and non-efficient factories. DEA is a method for analyzing a set of organizational units in order to identify the efficient units so that they can become benchmarks or peers for the inefficient units in the set and can facilitate the spread of best practice in a cooperative system.
\end{abstract}

Results: In this study, the findings related to codes and current efficiencies of factories in the model of production, the operation functioning with different efficiencies and the benchmarks of non-efficient operations according to the production model were obtained. As an example of the results of the efficiency analyses, for factory code F7 employing 19 laborers to work more efficiently, it must decrease the number of laborers to 18 . In addition, the sales rate in the internal market should be decreased from $50 \%$ to $46 \%$, while the external sales rates are to be increased by $4 \%$.

Conclusions: With this study we aimed to examine the efficiencies of marble factories in Afyonkarahisar city. We also give some recommendations to the administrators of the factories for upgrading their production levels by summarizing the deficiencies of the factories, related with the results of the study. We hope that following these recommendations, the efficiencies of the factories will increase, and with increased and efficient productions, the importance of Afyonkarahisar city will be the highest in Turkey.

Keywords: data envelopment analysis; efficiency analysis; marble factories

\section{Introduction}

One of the main reasons that developed countries are economically strong is the ability of these countries to benefit from their natural resources in the best way possible. The fact that the amount and values of the European Community member countries are high in terms of world marble trade reflects this situation very well. These countries import marble blocks from other countries and process incompletely processed marble slabs which are exported into the third world countries for added profits. $60 \%$ of the marble export in the world is carried out by six countries which are Italy, China, India, Spain, Brazil and South America has an important share. Out of these countries, while India, China, Brazil

(c) 2013 Saraçli et al.; licensee Springer. This is an Open Access article distributed under the terms of the Creative Commons Attribution License (http://creativecommons.org/licenses/by/2.0), which permits unrestricted use, distribution, and reproduction in any medium, provided the original work is properly cited. 
Table 1 Input and output variables used in the model of production

\begin{tabular}{ll}
\hline Model variables \\
\hline Inputs & Number of factory workers \\
& Number of engineers employed at the factory \\
& Number of machines in the factory \\
& Number of marble quarries belonging to the factory \\
& Ratio of produced products sold on the internal market (\%) \\
& Ratio of produced products sold on the external market (\%) \\
& Monthly costs of laborer employed in the factory \\
& Monthly electricity costs of the factory \\
& Monthly water costs of the factory \\
& Monthly maintenance costs of the factory \\
& Monthly fuel costs of the factory \\
Average monthly socket costs of the factory & Monthly produced processed marble amount $\left(\mathrm{m}^{2}\right)$ \\
Number of produced product varieties
\end{tabular}

and Finland export raw marble blocks, Italy, Spain, Portugal, Canada, Greece and South Korea are exporters of processed marble [1].

After the 1980s the production of marble in Turkey has increased in a major way. Particularly during the recent past, large companies have invested in integrated facilities, and with their inception there has been a significant increase in the production of processed marble. With the implementation of modern quarry production methods and state-ofthe-art techniques, Turkey is among the seven leading large producers of natural stone in the world [2]. Turkey is the seventh largest producer of marble and natural stone in the world and ranks eighth in exports [3].

The purpose of this study is to examine the efficiencies of marble factories in Afyonkarahisar city via data envelopment analysis (DEA), which is a mathematical programming-based analysis.

\section{Methods}

In this study, the efficiencies of 64 marble factories in Afyonkarahisar city, the most famous city in terms of marble production in Turkey, were examined. Input and output variables used to examine of efficiencies of the factories according to the model of production are given in Table 1. In this study, data envelopment analysis (DEA) was used to determine the efficient and non-efficient factories.

DEA approach differentiates decision-making units (DMUs) into two groups: efficient DMUs and inefficient DMUs. A DMU is efficient if it obtains the maximum score of 1; otherwise, it is inefficient. DEA also provides targets for inefficient units by improving inputs and outputs proportionally. On the other hand, in some cases, it may be impossible for an inefficient DMU to improve all of the inputs or outputs proportionally at the same time in order to be efficient. For these types of situations, measure-specific data envelopment models can be used. Measure-specific models take sets of specific inputs or outputs of interest and give the target values for only those factors [4].

Data envelopment analysis is a method for analyzing a set of organizational units in order to identify the efficient units so that they can become benchmarks or peers for the inefficient units in the set and can facilitate the spread of best practice in a cooperative system. Examples of the units are schools, bank branches and retail outlets and they typically involve multiple inputs being converted into multiple outputs. The DEA model was initially formulated as a deterministic model, but there have been numerous developments that 
take into account uncertainty including chance-constrained (CC) DEA, imprecise DEA (IDEA), Monte Carlo simulation and bootstrapping. The authors have used DEA to analyze various real-world situations involving, for example, local government departments, bank branches, universities and public houses. In these and other applications, DEA has been used deterministically and any uncertainty in the situation has been handled only implicitly or by sensitivity analysis [5].

DEA has generated a considerable amount of interest in the academic sector, and DEA practitioners have successfully applied the technique in assessing the efficiency of various organizations in the public and private sectors. However, managers and other decisionmakers in these DMUs have not always welcomed DEA with a similar enthusiasm. This lukewarm reception may be partly due to the fact that DEA results are difficult to convey when the number of the decision variables exceeds beyond a certain point [6]. DEA is a non-parametric productive efficiency measurement method for operations with multiple inputs and multiple outputs [7].

Data envelopment analysis (DEA) of Charnes, Cooper and Rhodes (CCR) model was developed by Charnes et al. [8] to evaluate the efficiency of decision-making units (DMUs). The CCR model was further studied and extended by many other researchers [9-15]. As the DEA involves many DMUs, some researchers [16-20] have investigated the possible relationship between DEA and multiobjective linear programming (MOLP) [21].

\section{CCR DEA model}

The DEA model developed by Charnes et al. [8] is a mathematical programming model that considers several inputs and outputs. This model assumes $n$ decision-making units (DMUs), with $m$ inputs and $p$ outputs, where the efficiency evaluation model of $k$ th DMU can be defined as in the following equation (1) [8]:

$$
\begin{aligned}
& \operatorname{Max} f_{k}=\frac{\sum_{r=1}^{p} u_{r} y_{r k}}{\sum_{i=1}^{m} v_{i} x_{i k}}, \\
& \text { s.t. } f_{k}=\frac{\sum_{r=1}^{p} u_{r} y_{r k}}{\sum_{i=1}^{m} v_{i} x_{i k}} \leq 1, \quad l=1,2, \ldots, n, \\
& u_{r} \geq \varepsilon, \quad r=1,2, \ldots, p, \\
& v_{i} \geq \varepsilon, \quad i=1,2, \ldots, m,
\end{aligned}
$$

where:

$x_{i l}$ : the $i$ th input value for $l$ th DMU

$y_{r l}$ : the $r$ th output value for the $l$ th DMU

$u_{r}$ : the weight values of the output

$v_{i}$ : the weight values of the input, $i$

$\varepsilon$ : and a very small positive value.

Obtaining the solution from equation (1) is difficult because it is a nonlinear programming problem. Charnes et al. [8] transformed equation (1) into a linear programming problem by assuming $\sum_{i=1}^{m} v_{i} x_{i k}=1[21]$.

\section{Results and discussion}

In this study, the findings related to codes and current efficiencies of factories in the model of production are showed in Table 2, the findings related to the operation functioning with 
Table 2 Codes and efficiencies of factories

\begin{tabular}{llllllll}
\hline $\begin{array}{l}\text { Factory } \\
\text { code }\end{array}$ & $\begin{array}{l}\text { Efficiency } \\
(\mathbf{\%})\end{array}$ & $\begin{array}{l}\text { Factory } \\
\text { code }\end{array}$ & $\begin{array}{l}\text { Efficiency } \\
(\mathbf{\%})\end{array}$ & $\begin{array}{l}\text { Factory } \\
\text { code }\end{array}$ & $\begin{array}{l}\text { Efficiency } \\
\text { (\%) }\end{array}$ & $\begin{array}{l}\text { Factory } \\
\text { code }\end{array}$ & $\begin{array}{l}\text { Efficiency } \\
\text { (\%) }\end{array}$ \\
\hline F1 & 100 & F17 & 100 & F33 & 100 & F49 & 100 \\
F2 & 100 & F18 & 100 & F34 & 100 & F50 & $\mathbf{5 9}$ \\
F3 & 100 & F19 & 100 & F35 & $\mathbf{9 . 2 3}$ & F51 & 100 \\
F4 & 100 & F20 & $\mathbf{8 8 . 3 2}$ & F36 & 100 & F52 & $\mathbf{7 9 . 7}$ \\
F5 & 100 & F21 & 100 & F37 & 100 & F53 & 100 \\
F6 & 100 & F22 & 100 & F38 & 100 & F54 & 100 \\
F7 & $\mathbf{9 4 . 4}$ & F23 & 100 & F39 & 100 & F55 & 100 \\
F8 & 100 & F24 & $\mathbf{9 0 . 7 9}$ & F40 & 100 & F56 & 100 \\
F9 & 100 & F25 & 100 & F41 & 100 & F57 & 100 \\
F10 & 100 & F26 & 100 & F42 & $\mathbf{4 6 . 1 5}$ & F58 & 100 \\
F11 & $\mathbf{4 1 . 5 2}$ & F27 & 100 & F43 & $\mathbf{7 0 . 1 6}$ & F59 & $\mathbf{3 5 . 9}$ \\
F12 & $\mathbf{5 2 . 7}$ & F28 & 100 & F44 & 100 & F60 & 100 \\
F13 & $\mathbf{6 8 . 0 9}$ & F29 & 100 & F45 & 100 & F61 & 100 \\
F14 & $\mathbf{4 6 . 8 1}$ & F30 & $\mathbf{3 6 . 8 0}$ & F46 & 100 & F62 & 100 \\
F15 & $\mathbf{8 3 . 8 7}$ & F31 & 100 & F47 & 100 & F63 & $\mathbf{7 0 . 1}$ \\
F16 & 100 & F32 & 100 & F48 & $\mathbf{1 8 . 7 9}$ & F64 & 100 \\
\hline
\end{tabular}

Table 3 The number of factories according to efficiencies

\begin{tabular}{ll}
\hline Efficiency & Frequencies \\
\hline An operation functioning with 100\% efficiency & 47 \\
An operation functioning with an efficiency between 80 and 100\% & 4 \\
An operation functioning with an efficiency between 70 and 80\% & 3 \\
An operation functioning with an efficiency between 60 and 70\% & 1 \\
An operation functioning with an efficiency between 50 and 60\% & 3 \\
An operation functioning below an efficiency of 50\% & 6 \\
\hline
\end{tabular}

Table 4 Benchmarks of non-efficient operations according to the production model

\begin{tabular}{llrl}
\hline Code & Efficiency & \multicolumn{1}{c}{ Benchmarks } \\
\hline F7 & $94.4 \%$ & $5(0.06) 10(0.49) 26(0.26) 56(0.02) 57(0.05) 61(0.05)$ \\
F11 & $41.52 \%$ & $8(0.12) 10(0.06) 26(0.03) 45(0.09) 56(0.03) 61(0.09)$ \\
F12 & $52.7 \%$ & $6(0.04) 9(0.15) 17(0.26) 26(0.07) 45(0.00) 57(0.00)$ \\
F13 & $68.09 \%$ & $6(0.34) 17(0.34)$ \\
F14 & $46.81 \%$ & $8(0.19) 19(0.10) 44(0.03) 45(0.06) 58(0.04) 61(0.05)$ \\
F15 & $83.87 \%$ & $8(0.04) 10(0.28) 22(0.19) 44(0.08) 45(0.16) 56(0.08) 57(0.02)$ \\
F20 & $88.32 \%$ & $6(0.13) 26(0.21) 45(0.01) 57(0.01) 61(0.20) 62(0.32)$ \\
F24 & $90.79 \%$ & $5(0.26) 6(0.12) 10(0.05) 26(0.34) 56(0.03) 57(0.05) 61(0.07)$ \\
F30 & $36.80 \%$ & $6(0.05) 10(0.03) 26(0.09) 56(0.20)$ \\
F35 & $9.23 \%$ & $5(0.01) 56(0.04) 57(0.04)$ \\
F42 & $46.15 \%$ & $28(0.15) 39(0.19) 45(0.12)$ \\
F43 & $70.16 \%$ & $9(0.20) 28(0.10) 34(0.17) 38(0.18) 57(0.04)$ \\
F48 & $18.79 \%$ & $8(0.13) 45(0.01) 56(0.03) 57(0.01) 58(0.01)$ \\
F50 & $59.09 \%$ & $39(0.08) 44(0.05) 45(0.08) 46(0.31) 57(0.22) 58(0.05)$ \\
F52 & $79.73 \%$ & $8(0.08) 44(0.07) 45(0.04) 46(0.17) 53(0.27) 57(0.09) 58(0.07)$ \\
F59 & $35.99 \%$ & $5(0.13) 9(0.02) 56(0.21) 57(0.00)$ \\
F63 & $70.12 \%$ & $6(0.32) 10(0.09) 17(0.02) 26(0.20) 45(0.03) 57(0.05)$ \\
\hline
\end{tabular}

different efficiencies are given in Table 3 and the benchmarks of non-efficient operations according to the production model are given in Table 4 .

According to the findings given in Table 2, it was determined that there are 17 factories whose efficiency is under $100 \%$ (or non-effective). It was detected that the efficiency of six factories is under $50 \%$ (Table 3 ).

According to the findings given in Table 4, factory code F7 with an efficiency score of $94.4 \%$ was unable to operate efficiently because of the $80 \%$ negative impact of the input 
variable, which is the number of laborers. Factory code F7 is 6\% similar to factory code F5, $49 \%$ similar to factory code F10, 26\% similar to factory code F $26,2 \%$ similar to factory code F56, 5\% similar to factory code F57 and 5\% similar to factory code F61.

As a result of the analyses which were carried out, in order for factory code F7 employing 19 laborers to work more efficiently, it must decrease the number of laborers to 18. In addition, the sales rate in the internal market should be decreased from $50 \%$ to $46 \%$, while the external sales rates are to be increased by $4 \%$.

The reason why factory code F11 functioning with an efficiency score of $41.52 \%$ is not functioning efficiently is because of the input variable being the number of laborers and the output variable which is production. Production which has a major impact on efficiency and the number of laborers should be reviewed in factory code F11. This factory which employs 13 laborers should decrease the number of laborers to 6 . In addition, this factory which processes $5,000 \mathrm{~m}^{3}$ of marble per month can function more efficiently if the amount of processed marble is increased to $5,055 \mathrm{~m}^{3}$.

The efficiency score of factory code F12 was determined to be $52.7 \%$. The reason this operation is unable to function with a $100 \%$ efficiency is due to the input variables which are the number of laborers, ratio of internal market sales and the monthly costs of the laborers. Factory code F12 must decrease its number of laborers from 18 to 10, decrease its internal market sales rate from $70 \%$ to $37 \%$ and decrease its monthly laborers costs from $17,000 \mathrm{TL}$ to $8,805 \mathrm{TL}$. In addition, factory code F12 is 5\% similar to factory code F6, 15\% similar to factory code F9, 26\% similar to factory code F17 and 7\% similar to factory code F26.

The reason why factory code F13 with an efficiency score of $68.09 \%$ failed in functioning efficiently is due to the input variables which are the number of laborers and the monthly electricity costs. In addition, the effective function of this operation is affected by the output variables of production and product variety. In order for factory code F13 to function efficiently, it must decrease the number of laborers from 15 to 10, decrease monthly laborer costs from 11,000 TL to 9,690 TL and reduce the monthly electricity costs from 7,250 TL to $6,790 \mathrm{TL}$. In terms of the output variables, the monthly production must be decreased from $8,000 \mathrm{~m}^{3}$ to $7,990 \mathrm{~m}^{3}$ and the variety of products should be decreased from six to three. The resemblance ratio of this operation with other operations is realized in terms of a 34\% similarity to factory code F6 and a 34\% similarity to factory code F17.

Factory code F14 with an efficiency score of $46.81 \%$ has a $19 \%$ similarity with factory code F8, 10\% similarity with factory code F18, 3\% similarity with factory code F44, 6\% similarity to factory code F45, 4\% similarity to factory code F58 and a 5\% similarity to factory code F61. The inefficient function of this operation was caused by the input variables which are the number of laborers as well as monthly laborer and electricity costs. In addition, the output variable of monthly production amount also has an impact on the inefficient functioning of this operation. In order for factory code F14 to function more efficiently, the number of laborers must be reduced from 10 to 5 , the monthly laborer costs must be reduced from $8,500 \mathrm{TL}$ to $4,917 \mathrm{TL}$ and the monthly electricity costs must be reduced from 4,500 TL to $2,360 \mathrm{TL}$. The output variable monthly production amount must be increased from $4,250 \mathrm{~m}^{3}$ to $4,280 \mathrm{~m}^{3}$.

The efficiency score for factory code F15 was determined to be $83.87 \%$. The reason for the inefficient functioning of this operation is due to the output variable which is the number of laborers and the input variable which is the monthly production amount. In 
order for factory code F15 to function more efficiently, the number of laborers must be reduced from 12 to 10 and the monthly production amount must be increased from 9,000 to $9,080 \mathrm{~m}^{3}$. In addition, the ratio of similarities of this operation with the others is $4 \%$ with factory code F8, 28\% with factory code F10, 19\% with factory code F22, 8\% with factory code F44, 16\% with factory code F45, 8\% with factory code F56 and 2\% with factory code F57.

The reason factory code F20 with its $88.32 \%$ efficiency was unable to function with a $100 \%$ efficiency is due to the input variable which is the number of laborers. In order to function more efficiently, this operation must reduce its number of laborers from 18 to 16 . In addition, the ratio of similarities of this operation with the others is $13 \%$ with factory code F6, 21\% with factory code F $26,1 \%$ with factory code F45, $1 \%$ with factory code F57, $20 \%$ with factory code F61, and 32\% with factory code F62.

The similarities ratio of factory code F24 with an efficiency score of $90.79 \%$ is $26 \%$ with factory code F5, 12\% with factory code F6, 5\% with factory code F10, 34\% with factory code F26, 3\% with factory code F56, 5\% with factory code F57 and 7\% with factory code F61. The inefficient function of this operation is due to the number of laborers and the monthly production amount. The operation must reduce its number of laborers from 22 to 20 and increase the monthly production amount from $15,500 \mathrm{~m}^{3}$ to $15,710 \mathrm{~m}^{3}$.

In order to function more efficiently, factory code F30 with its efficiency score of $36.8 \%$ must reduce its input variable of 22 laborers to 8 . In addition the output variable of monthly production amount must be increased from $7,000 \mathrm{~m}^{3}$ to $7,075 \mathrm{~m}^{3}$. The similarity ratio of this operation to other operations is $5 \%$ with factory code $\mathrm{F} 6,3 \%$ with factory code F10, 9\% with factory code F26, 20\% with factory code F56.

The efficiency score of factory code F35 as calculated to be $9.23 \%$. In order for this operation to function with a more efficient score, the input variable of 30 laborers must be reduced to 3 . In addition, the similarity ratio of this operation with the others is $1 \%$ with factory code F5, 4\% with factory code F56 and 4\% with factory code F57.

The inefficient functioning of factory code F 42 with its $46.15 \%$ efficiency score is due to the input variables consisting of the number of laborers, variety of machinery and monthly laborer costs. The number of laborers employed by this operation must be reduced from 11 to 5 , the number of machines must be reduced from 6 to 3 and the monthly laborer costs must be reduced from $15,000 \mathrm{TL}$ to $8,975 \mathrm{TL}$. In addition, the similarity of factory code F42 with other operations is 15\% with factory code F28, 19\% with factory code F39 and $12 \%$ with factory code F45.

The similarity ratio of factory code F43 which functions with an efficiency score of $70.16 \%$ with other operations is $20 \%$ with factory code F9, $10 \%$ with factory code F28, $17 \%$ with factory code F34, 18\% with factory code F38 and 4\% with factory code F57. In addition, in order for this operation to achieve a more efficient score, the input variable of the number of laborers must be reduced from 16 to 11 . Another input variable which must be altered is the reduction of monthly laborers costs from $16,000 \mathrm{TL}$ to $11,874 \mathrm{TL}$.

The reason why factory code F48 with its efficiency score of $18.79 \%$ cannot function more effectively is due to the input variables of too many laborers and excessive monthly laborer costs. In order for this operation to achieve an efficient score, the number of laborers must be reduced from 14 to 3 and the monthly laborer costs must be reduced from 9,000 TL to 2,573 TL. In addition the similarity ratio of this operation with the others is 
rated as $13 \%$ with factory code F8, $1 \%$ with factory code F 45 , $3 \%$ with factory code F56, $1 \%$ with factory code F57 and 1\% with factory code F58.

Factory code F50 which has an efficiency score of $59.09 \%$ has a similarity ratio with other operations rated as $8 \%$ with factory code F39, $5 \%$ with factory code F44, 8\% with factory code F45, 31\% with factory code F $46,22 \%$ with factory code F57 and 5\% with factory code F58. In order for factory code F50 to function effectively, the number of laborers must be reduced from 12 to 9 .

In order for factory code F52 which functions with an efficiency score of $79.73 \%$ to be fully efficient, the input variables of the number of laborers must be reduced from 12 to 10 and the number of machines must be reduced from 10 to 8 . In addition, it has been determined that the similarity ratio of this operation with the others is $8 \%$ with factory code F8, 7\% with factory code F44, 4\% with factory code F45, 17\% with factory code F46, $27 \%$ with factory code F53, 9\% with factory code F57 and 7\% with factory code F58.

The efficiency score of factory code F59 has been determined to be $35.99 \%$. In order for this operation to become $100 \%$ efficient, the input variable of the number of laborers must be reduced from 27 to 9 . In addition, the similarity ratio of this operation with the others is $13 \%$ with factory code F5, 2\% with factory code F9 and 21\% with factory code F56.

The reason for the inefficiency of factory code F63 with its efficiency score of $70.12 \%$ is due to the input variable of the number of laborers. If the operation reduces its number of 18 laborers to 13, it will be able to operate efficiently. In addition, the similarity ratio of this operation with the others is $32 \%$ with factory code F6, 9\% with factory code F10, $2 \%$ with factory code F17, 20\% with factory code F26, 3\% with factory code F45 and 5\% with factory code F57.

\section{Conclusions}

Whereas Afyonkarahisar city is one of the leading cities in Turkey according to marble production and exportation, the production level is lower according to extracted raw materials. With this study we aimed to examine the efficiencies of marble factories in Afyonkarahisar city, we also gave some recommendations to the administrators of the factories for upgrading their production levels by summarizing the deficiencies of the factories, related with the results of the study.

We hope that following these recommendations the efficiencies of the factories will increase, and with increased and efficient productions, the importance of Afyonkarahisar city will be the highest in Turkey.

Competing interests

The authors declare that they have no competing interests.

Abbreviations

CC: Chance-Constrained; CCR: Charnes, Cooper and Rhodes model; DEA: Data Envelopment Analysis; DMUs: Decision-Making Units; IDEA: Imprecise Data Envelopment Analysis; MOLP: Multiobjective Linear Programming

Authors' contributions

SS has made substantial intellectual and theoretical contributions in order to carry out this study and also has determined the research design as well as coordinated all the process. IK has played a role in statistical analysis and interpretation of data. CG and iD made various interviews and have played a significant role in the collection of the data set. All authors read and approved the final manuscript.

\section{Author details}

1 Department of Statistics, Faculty of Art and Science, Afyon Kocatepe University, Afyonkarahisar, TR-03200, Turkey.

${ }^{2}$ Department of Biostatistics, Faculty of Veterinary Medicine, Afyon Kocatepe University, Afyonkarahisar, TR-03200, Turkey. 


\section{Acknowledgements}

Dedicated to Professor Hari M Srivastava.

This study is funded by Afyon Kocatepe University Scientific Research Projects Unit (Project No: 11FENED09).

Received: 31 December 2012 Accepted: 8 March 2013 Published: 2 April 2013

\section{References}

1. Özmen, M: Kasım 2000 - Şubat 2001 Ekonomik Krizleri ve Göller Bölgesi Mermercilik Sektörüne Etkileri. Yüksek Lisans Tezi, Süleyman Demirel Üniversitesi Sosyal Bilimler Enstitüsü Iktisat Anabilim Dalı, Isparta (2003)

2. Çapik, M, Çavuşoğlu, İ, Yılmaz, AO: Türkiye Doğal Taş Sektörüne Genel Bir Bakış. In: Ersoy, M, Çelik, MY, Yeşilkaya, L (eds.) Mersem'7 Uluslararası Mermer ve Doğal Taş Kongresi Bildiriler Kitabı, Afyonkarahisar (2010)

3. Çetin, T: Türkiye Mermer Potansiyeli, Üretimi ve Ihracatı. Gazi Eğitim Fakültesi Dergisi 1, 243-256 (2003)

4. Ulucan, A: Measuring the efficiency of turkish universities using measure-specific data envelopment analysis. Sosyoekonomi 1, 182-196 (2011)

5. Dyson, RG, Shale, EA: Data envelopment analysis, operational research and uncertainty. J. Oper. Res. Soc. 61, 25-34 (2010)

6. Mahgary, SE, Lahdelma, R: Data envelopment analysis: visualizing the results. Eur. J. Oper. Res. 85, 700-710 (1995)

7. Liu, JS, Lu, LYY, Lu, WM, Lin, BJY: Data envelopment analysis 1978-2010: a citation-based literature survey. Omega 41, 3-15 (2013)

8. Charnes, A, Cooper, WW, Rhodes, E: Measuring efficiency of decision making units. Eur. J. Oper. Res. 2, 429-444 (1978)

9. Chang, KP, Kao, PH: The relative efficiency of public versus private municipal bus firms: an application of data envelopment analysis. J. Product. Anal. 3, 63-80 (1992)

10. Kao, C: Efficiency improvement in data envelopment analysis. Eur. J. Oper. Res. 78, 1-8 (1994)

11. Murphy, GB, Trailer, JW, Hill, RC: Measuring performance in entrepreneurship research. J. Bus. Res. 36, 15-23 (1996)

12. Athanassopoulos, A: Goal programming and data envelopment analysis (GoDEA) for target-based multi-level planning: allocating central grants to the Greek local authorities. Eur. J. Oper. Res. 87, 535-550 (1995)

13. Karlaftis, MG: A DEA approach for evaluating the efficiency and effectiveness of urban transit systems. Eur. J. Oper. Res. 152, 354-364 (2004)

14. Amin, GR, Toloo, M, Sohrabi, B: An improved MCDM DEA model for technology selection. Int. J. Prod. Res. 44, 2681-2686 (2006)

15. Cook, WD, Seiford, LM: Data envelopment analysis (DEA) - thirty years on. Eur. J. Oper. Res. 192, 1-17 (2009)

16. Golany, B: An interactive MOLP procedure for the extension of DEA to effectiveness analysis. J. Oper. Res. Soc. 39, 725-734 (1988)

17. Roll, Y, Cook, WD, Golany, B: Controlling factor weights in data envelopment analysis. IIE Trans. 23, 2-9 (1991)

18. Roll, Y, Golany, B: Alternative methods of treating factor weights in DEA. Omega 21, 99-103 (1993)

19. Karsak, EE, Ahiska, SS: A common-weight MCDM framework for decision problems with multiple inputs and outputs. In: Gervasi, O, Gavrilova, M (eds.) Computational Science and Its Applications - ICCSA 2007. Lect. Notes Comput. Sci., vol. 4705, pp. 779-790. Springer, Berlin/Heidelberg (2007)

20. Karsak, EE, Ahiska, SS: Practical common weight multicriteria decision-making approach with an improved discriminating power for technology selection. Int. J. Prod. Res. 43, 1537-1554 (2005)

21. Chen, YW, Larbani, M, Chang, YP: Multiobjective data envelopment analysis. J. Oper. Res. Soc. 60, 1556-1566 (2009)

doi:10.1186/1029-242X-2013-139

Cite this article as: Saraçli et al.: An application of data envelopment analysis on marble factories. Journal of Inequalities and Applications 2013 2013:139.

\section{Submit your manuscript to a SpringerOpen ${ }^{\circ}$ journal and benefit from:}

- Convenient online submission

- Rigorous peer review

Immediate publication on acceptance

- Open access: articles freely available online

- High visibility within the field

- Retaining the copyright to your article 